\section{Mapeamento da pesquisa em Jornalismo Móvel no Brasil (2005-2020)}

\author{
Maíra Evangelista de Sousa
}

\begin{abstract}
Resumo:
Os processos de produção, circulação e consumo de notícias por meio de dispositivos móveis e as investigações no âmbito do jornalismo móvel surgiram, sobretudo, a partir do início dos anos 2000. Nesse sentido, o objetivo do presente artigo é identificar as características da pesquisa em jornalismo móvel produzida em Programas de Pós-Graduação do Brasil. O corpus do trabalho é composto por sessenta (60) estudos - sendo dezesseis (16) teses e quarenta e quatro (44) dissertações - finalizados entre os anos de 2005 e 2020. Trata-se de um artigo de caráter descritivo-analítico que combina técnicas qualitativas e quantitativas. As teses e dissertações são avaliadas em relação a seis categorias: ano de finalização, Programas de Pós-Graduação, regiões do Brasil, temáticas, suportes e organizações jornalísticas.
\end{abstract}

Palavras-chave: Jornalismo Móvel. Pesquisa em Jornalismo. Mapeamento.

\section{Mapping the research in Mobile Journalism in Brazil (2005-2020)}

\begin{abstract}
:
The processes of production, circulation and consumption of news through mobile devices and the investigations in the field of mobile journalism emerged, especially, from the beginning of the 2000s. The purpose of this article is to identify the characteristics of mobile journalism research developed in Brazilian Postgraduate Programs. The corpus of this work consists of sixty (60) studies - sixteen (16) theses and forty-four (44) dissertations - completed between the years of 2005 and 2020. It is a descriptive-analytical article that combines qualitative and quantitative techniques. The theses and dissertations are evaluated regarding six categories: year of completion, Postgraduate Programs, Brazilian region, themes, supports and journalistic organizations.
\end{abstract}

Keywords: Mobile Journalism. Research in Journalism. Mapping.
Recebido em: 20.03 .20

Aprovado em: 13.09.21

Maíra Evangelista de Sousa

Docente do Programa de Pós-Graduação em Comunicação, Linguagens e Cultura (PPGCLC) e dos cursos de Comunicação Social da Universidade da Amazônia (UNAMA).

E-mail: maira.evangelistadesousa@gmail.com 
${ }^{1}$ Como a coleta de dados foi realizada em julho de 2021, optou-se pela seleção

de pesquisas finalizadas nos anos já encerrados. No caso, até 2020 .

${ }^{2}$ Disponível em: http:// bdtd.ibict.br/. Acesso em: 10 jul. 2021.

${ }^{3}$ Disponível em: http:// bancodeteses.capes.gov.br/. Acesso em: 10 jul. 2021.

${ }^{4}$ Short Message Service.

${ }^{5}$ Wireless Application Protocol.

${ }^{6}$ Personal Digital Assistant. mobilidade é entendida como uma das marcas fundamentais do século XXI (HANNAM; SHELLER; URRY, 2006), o qual é caracterizado pela cultura da mobilidade (LEMOS, 2009) e pela sociedade móvel (AGUADO; MARTÍNEZ, 2008a). Foi a partir dos anos 2000, que o Jornalismo Móvel entrou, efetivamente, na pauta tanto dos veículos jornalísticos que passaram a produzir e a distribuir conteúdos em dispositivos móveis quanto das investigações do campo de estudos do jornalismo que começaram a pesquisar esse fenômeno.

Este artigo busca identificar características da pesquisa em jornalismo móvel produzida em Programas de Pós-Graduação do Brasil, da área de Comunicação e Informação. O corpus da investigação é formado por sessenta (60) trabalhos finalizados entre os anos de 2005 e $2020^{1}$, sendo dezesseis (16) teses e quarenta e quatro (44) dissertações.

Este estudo de caráter descritivo-analítico se deu em dois momentos: 1) coleta de dados - realizada em duas bases de dados acadêmicas do país: a Biblioteca Digital Brasileira de Teses e Dissertações (BDTD) ${ }^{2}$ e o Banco de Teses e Dissertações da Capes $^{3}$ - e seleção do material; 2) descrição e análise baseadas em seis categorias: ano de finalização, Programas de Pós-Graduação, regiões do Brasil, temáticas, suportes e organizações jornalísticas. As abordagens qualitativa e quantitativa foram usadas de forma complementar (LOPES, 2010).

\section{O Jornalismo Móvel}

Há diferentes compreensões quanto à abordagem entre jornalismo e mobilidade. Há autores que entendem que a relação entre ambos sempre existiu (PELLANDA, 2005; SHELLER, 2015; SILVA, 2013) e existem autores que consideram as capacidades telefônicas e computacionais dos dispositivos móveis fundamentais para que a portabilidade não seja tratada como sinônimo de mobilidade (REZENDE, 2016; SILVEIRA, 2017). Neste artigo, compreende-se que a relação histórica entre jornalismo e mobilidade se complexifica e se amplia conforme surgem novos dispositivos.

A mobilidade é tida como uma característica central do jornalismo (DUFFY et al., 2021). Já o jornalismo móvel é considerado uma subárea emergente dos estudos de jornalismo (REZENDE, 2016). A produção, a circulação e o consumo de informações noticiosas em dispositivos móveis foi possível graças ao processo de miniaturização de telefones e de computadores somado à emergência da internet móvel (GOGGIN, LING; HJORTH, 2015; PELLANDA, 2009; WESTLUND, 2013, 2014). Por muitos anos, telefones e computadores foram caracterizados pelo gigantismo e pela imobilidade (PALACIOS, 2013).

Os serviços de telefonia móvel estavam disponíveis desde a década de 1960, mas foi somente a partir do final de 1970 e início de 1980 que começaram a ser comercializados (GOGGIN; LING; HJORTH, 2015; PALACIOS, 2013; PELLANDA, 2005). A telefonia móvel é caracterizada em gerações. A primeira foi a analógica. Os celulares digitais surgem na década de 1990 com a segunda geração (2G), possibilitando o envio e o recebimento de $\mathrm{SMS}^{4}$ e a navegação na internet por meio do protocolo WAP ${ }^{5}$. Atualmente, as principais formas de acesso à internet móvel são a banda larga (wi-fi) e o $4 \mathrm{G}$ e $5 \mathrm{G}$ que possuem velocidade de conexão muito maior do que as gerações iniciais. A sexta geração $(6 \mathrm{G})$ ainda está em desenvolvimento.

Lançado em 1993, o $\mathrm{PDA}^{6}$ é considerado a forma primitiva de acessar a internet móvel (PELLANDA, 2005). Contudo, os marcos da comunicação móvel foram os lançamentos do iPhone e do $i P a d$, em 2007 e 2010, respectivamente (PELLANDA, 2009).

Os dispositivos móveis são artefatos dotados de conectividade ubíqua e concebidos para a portabilidade cotidiana (AGUADO; CASTELLET, 2013). Eles são 
considerados meta-dispositivos tecnológicos por oferecerem diversas funcionalidades, em um único aparelho e têm como principais características: a ubiquidade, a conectividade contínua e à demanda, a sensibilidade ao contexto e ao usuário (AGUADO; MARTÍNEZ, 2008b).

Desde o início do século XXI, Pavlik (2001) e Quinn (2002) discutiam questões relacionadas ao uso de tecnologias digitais móveis na produção jornalística. Ambos já apontavam aspectos relacionados à sala de redação virtual. Em 2009, Quinn conceitua o que seria o mojo (abreviação para jornalista móvel, no inglês): "usa apenas um telefone celular para reunir e distribuir notícias. Essa notícia pode consistir em texto, áudio, fotos ou vídeos, ou às vezes uma combinação destes. Mojos tendem a trabalhar sozinhos" (QUINN, 2009, p. 10, tradução nossa).

Silva (2013, p. 321) observa que o uso de tecnologias digitais móveis na produção jornalística desempenha "uma função central na ampliação e reconfiguração das rotinas como tendência para o modelo multiplataforma e em mobilidade". Dentre as principais transformações estão: o acúmulo de funções, as novas demandas por atualizações contínuas - sobretudo no trabalho externo, os níveis de comprometimento da produção da notícia em condições de mobilidade. Marques (2017), por sua vez, aponta mudanças na produção da pauta, com repercussão nos processos de produção, edição e distribuição dos conteúdos. Já Abreu (2021) indica características relativas à produção jornalística com dispositivos móveis: agilidade, praticidade, ubiquidade, polivalência, participação, trabalho contínuo, métricas, mobile/digital first e qualidade da internet. Para a autora, a análise de métricas é uma nova etapa da rotina produtiva com smartphones.

Canavilhas (2021) aponta como modificações provocadas pelos dispositivos móveis na produção jornalísticas: a possibilidade de contato permanente entre repórter e redação; a substituição dos equipamentos de captura de imagem por smartphones; a diminuição do tempo entre o acontecimento e a publicação da notícia; o fortalecimento do trabalho dos mojos; a participação do público no processo de construção noticiosa.

Nesse cenário, a distribuição de conteúdos em múltiplas plataformas é entendida como uma estratégia dos veículos jornalísticos para ampliar os seus contratos de comunicação junto ao público (BELOCHIO, 2012). No final da década de 1990, ocorreram as primeiras publicações noticiosas para o pager (WESTLUND, 2013). No início dos anos 2000, iniciaram os serviços de envio de informações jornalísticas por meio de SMS e $\mathrm{MMS}^{7}$ para celulares por veículos como $B B C, E l$ País, The Sun (FIDALGO, 2009). Em seguida, foram criados os sites móveis que, até 2006, eram acessados através de navegadores do celular (WESTLUND, 2013).

No Brasil, a primeira experiência ocorreu, em 2000, quando o jornal Folha de S. Paulo lançou o FolhaWAP. Ainda naquele ano, o Estado de S. Paulo e a Editora Abril lançaram portais WAP, sendo que a Editora Abril também inaugurou o serviço de notícias via SMS (FERREIRA, 2005; CARMO, 2008).

Em 2007, jornais como The New York Times, El País e Le Monde criaram aplicativos específicos para iPhone (FIDALGO, 2009; WESTLUND, 2013). Em 2009, com o lançamento do Kindle, veículos como The New York Times, Washington Post e Le Monde também iniciaram experiências no suporte. Em 2011, foram criados produtos jornalísticos específicos para iPad. O pioneiro foi o The Daily. Logo depois, foram lançados os jornais vespertinos - publicados ao final da tarde. O primeiro foi o iPad Evening Edition (CANAVILHAS; SATUF, 2013).

No Brasil, O Estado de S. Paulo lançou o primeiro aplicativo para iPhone, em 2009. No mesmo ano, O Globo e Zero Hora começaram a publicar conteúdos no Kindle. Em 2010, surgiram as experiências iniciais para iPad pelos jornais O Estado de S. Paulo e O Globo (SOUSA, 2018). Mais tarde, em 2012, estrearam as versões vespertinas O Globo A Mais e Estadão Noite (CANAVILHAS; SATUF, 2013).

${ }^{7}$ Multimedia Messaging Service. 
Quanto às tecnologias vestíveis, as experiências iniciais com óculos e relógios inteligentes foram realizadas pelo The Guardian (SOUZA, 2014). No Brasil, o G1 e o UOL começaram a enviar notificações para relógios inteligentes a partir de 2015 (SOUSA, 2016).

$\mathrm{Na}$ tentativa de sistematizar essa trajetória, Pellanda et al. (2017) estabelecem sete marcos de tecnologias apropriadas pelo jornalismo móvel: SMS; WAP; web móvel; iPhone, web apps e disseminação de produtos móveis, via lojas virtuais; notificações móveis; tecnologias vestíveis; inteligência artificial e assistentes pessoais. Já Empinotti (2020) propõe quatro fases para o jornalismo em mobilidade: formatos primitivos, marcada pelos telefones celulares convencionais, com serviços de $S M S$, portais WAP, alertas via e-mail, RSS; fase pré-app, caracterizada pelos primeiros smartphones e e-readers com serviços de MMS, streaming de conteúdo, web móvel, rede 3G; economia dos apps, distinguida pelos smartphones e tablets com serviços de lojas virtuais de apps, design responsivo, redes sociais; renovação, assinalada pelas tecnologias vestíveis com serviços de inteligência artificial, realidade aumentada.

Nesse sentido, Sousa (2016) sugere que uma nova fase do jornalismo móvel se delineia a partir de tecnologias vestíveis como relógios inteligentes e óculos de realidade virtual. Essa nova fase seria marcada pelo uso de artefatos que possibilitem a produção, a circulação e o consumo de conteúdos de forma ainda mais ubíqua.

Em relação aos produtos, Paulino (2017) explica que se inicialmente as páginas da web acessadas por meio de dispositivos móveis eram reformatadas para o tamanho da tela do navegador, mais tarde foram criados websites responsivos que possibilitaram uma visualização mais adaptada dos conteúdos em dispositivos móveis. Cunha (2015), por sua vez, define três perfis de aplicativos jornalísticos para esses suportes: o transpositivo, uma versão mais simples de aplicativo que traz o conteúdo tal como foi impresso; o híbrido, um aplicativo que mescla as características do impresso, da web e das funcionalidades dos dispositivos móveis; o autóctone, uma versão de aplicativo que é originalmente desenhada para o suporte móvel e explora novas práticas de produção, de consumo e de modelos de negócios.

Os dispositivos móveis possuem funcionalidades específicas: a tactilidade, a nivelabilidade, a opticabilidade, a locabilidade (PALACIOS et al., 2015). Desse modo, os produtos desenvolvidos para esses artefatos "revestem-se de novas propriedades na sua interface e em seu hardware que potencializam interações com especificidades que vão além das características da produção para a web ou para a mídia impressa" (p. 7). As características do formato da narrativa nesses suportes, segundo Silveira (2017), são: geolocalização, conexão entre dispositivos, navegação em camadas, personalização e fluxo de conteúdos, redistribuição, contextualização, integração ao sistema e boa usabilidade.

Oliveira (2017) afirma que embora os dispositivos móveis possuam características específicas que estimulam narrativas mais criativas e contextualizadas, é prematuro afirmar que neles haja uma transformação de formatos e gêneros jornalísticos. Já Empinotti (2020) explica que há uma tendência de subutilização das funcionalidades dos dispositivos. De modo semelhante, Alexandre (2021) observa que grande parcela dos aplicativos jornalísticos investe na transposição ou adaptação do conteúdo, evidenciando que ainda há muito a ser explorado.

O consumo de conteúdos jornalísticos em dispositivos móveis pode ocorrer em qualquer lugar e momento. Os smartphones favorecem o imediatismo (AGUADO; CASTELLET, 2013) e possibilitam uma maior portabilidade, podendo ser colocados no bolso da calça ou na bolsa (BARBOSA; SEIXAS, 2013) e criando um cordão umbilical entre quem informa e é informado (FIDALGO; CANAVILHAS, 2009). Já a relação dos tablets com o público não é tão próxima devido ao tamanho da tela que lembra um computador de mesa com maior portabilidade (CANAVI- 
LHAS, 2013). Quanto menor o tamanho do dispositivo, mais individual e portátil é o consumo de notícias. Inicialmente, a interação do público com esses suportes se dava pelo toque na tela. Mais tarde, começa a ganhar espaço também a interação por meio da voz (CANAVILHAS, 2021).

Os dispositivos móveis favorecem a mudança do sistema pull para o sistema push, de modo que não é mais o público que vai atrás da informação, mas a informação que chega até o público (FIDALGO; CANAVILHAS, 2009), por meio de sites de redes sociais, agregadores de conteúdo, notificações. Além de consumir informações, o público contribui para o fluxo informacional por meio de ações participativas (PAVLIK, 2014). Formatos oriundos de dispositivos móveis e sites de redes sociais - livestreaming, GIFs, emojis e memes - favorecem o engajamento do público (HILL; BRADSHAW, 2019). Cada indivíduo pode escolher o lugar, o momento, o conteúdo e o formato que deseja consumir informações jornalísticas. Contudo, cada vez mais o conteúdo é personalizado e moldado com precisão para cada indivíduo por sistemas algorítmicos e tecnologias de inteligência artificial (SALAVERRÍA; LIMA-SANTOS, 2020).

Segundo Hill e Bradshaw (2019), os dispositivos móveis e os sites de redes sociais são dois lados da mesma moeda; as estratégias mobile-first e user-centred estão no centro de discussão dos veículos jornalísticos; é importante os jornalistas terem conhecimento de codificação e de como gerar receitas com conteúdo digital. Já para Salaverría (2016) o futuro do jornalismo móvel será o jornalismo ubíquo que é definido como:

o tipo de jornalismo que, graças ao uso intensivo de sistemas algorítmicos e inteligência artificial, dissemina notícias em múltiplos dispositivos digitais produzidas por jornalistas, usuários e robôs, para que sejam consumidas em qualquer lugar e a qualquer hora pelo público, através de um fluxo constante de informações personalizadas e multissensoriais (SALAVERRÍA; LIMA-SANTOS, 2020, p. 12, tradução nossa).

Assim como a sociedade, o Jornalismo - a prática e a pesquisa - passa por transformações, visto que não se trata de algo estável, mas sim de algo fluido e em constante mudança. Nesse sentido, "permanecer ligado a esses preceitos clássicos fixos pode desinformar qualquer pessoa que se esforce para estabelecer a trajetória do jornalismo" (DUFFY et al., 2021, tradução nossa).

Se inicialmente o desafio do jornalismo móvel estava "nas demandas de uma sociedade conectada à internet cuja forma de comunicação é ubíqua" (MIELNICZUK, 2013, p. 113), mais tarde passa a estar em conteúdos falsos, trolls, filtros bolha, algoritmos (HILL; BRADSHAW, 2019) e reportagens imersivas (realidade virtual, realidade aumentada e vídeos $360^{\circ}$ ) (FONSECA, 2020). Tais mudanças demonstram a volatilidade deste campo de investigação.

\section{O Percurso Metodológico}

Com o intuito de identificar as características da pesquisa em jornalismo móvel em Programas de Pós-Graduação do Brasil, optou-se por um estudo de caráter descritivo-analítico realizado por meio de uma combinação de técnicas qualitativas e quantitativas. Embora os fundamentos das análises qualitativa e quantitativa sejam bem definidos, é cada vez mais difícil, de acordo com Lopes (2010, p. 154), apontar limites exatos entre esses dois tipos de pesquisa. Assim como os estudos quantitativos se apoiam em dados qualitativos, as investigações qualitativas preveem a quantificação das informações coletadas. Desse modo, após a organização, tabulação e quantificação dos materiais, o pesquisador volta-se para a qualificação dos mesmos, não havendo uma oposição, mas sim, uma complementaridade (LOPES, 2010).

Dividiu-se, para fins esquemáticos, os procedimentos metodológicos da presente investigação em dois momentos. A primeira etapa é constituída pela coleta de dados e pela seleção do material. A segunda, pela descrição e pela análise. 


\section{$1^{\text {a }}$ etapa}

Coleta de dados:

Buscou-se por teses e dissertações realizadas em Programas de Pós-Graduação (PPG) do Brasil que apresentassem palavras relacionadas à "mobilidade" articuladas com termos referentes ao "jornalismo" ou à "comunicação" nas duas principais bases de dados acadêmicas do Brasil: Biblioteca Digital Brasileira de Teses e Dissertações (IBICT) e Catálogo de Teses e Dissertações da Capes. O levantamento foi realizado em julho de 2021.

$\mathrm{Na}$ Biblioteca Digital Brasileira de Teses e Dissertações, combinou-se as palavras "mobilidade", "móveis", "móvel", "celular", "smartphone", "tablet", "aplicativo", "multiplataforma", "multitelas", "ubíqua", "ubíquo" e "ubiquidade" com "jornalismo", "imprensa", "jornal”, "jornais", "notícia”, "comunicação" e "mídia”. Todos os termos foram procurados nos campos "título" e "assunto" da "Busca avançada", resultando em 168 combinações.

Já no Catálogo de Teses e Dissertações da Capes, buscou-se por: "mobilidade", "móveis", "móvel", "celular", "smartphone", "tablet", "aplicativo", "multiplataforma", "multitelas", "ubíqua", "ubíquo" e "ubiquidade". Em seguida, aplicou-se os filtros: "Nome do programa" e "Área de concentração" com as palavras "jornalismo", "comunicação" e "mídia". Depois da leitura de todos os títulos das pesquisas, coletou-se apenas aquelas que traziam um dos termos buscados ("mobilidade", "móveis", "móvel", "celular", "smartphone", "tablet", "aplicativo", "multiplataforma”, "multitelas", "ubíqua", "ubíquo" ou "ubiquidade") e que não tinham surgido na pesquisa do IBICT.

Com esse levantamento, localizou-se pesquisas produzidas em oito das grandes áreas do conhecimento definidas pela Coordenação de Aperfeiçoamento de Pessoal de Nível Superior (Capes) ${ }^{8}$ : Ciências Exatas e da Terra, Ciências Biológicas, Engenharias, Ciências da Saúde, Ciências Sociais Aplicadas, Ciências Humanas, Linguística, Letras e Artes, Multidisciplinar.

Seleção do material:

Observando as pesquisas da área de Comunicação e Informação, inclusas na grande área Ciências Sociais Aplicadas, verificou-se a existência de variadas abordagens, as quais foram divididas em oito eixos de semelhança principais:

- Usos, apropriações e sociabilidade em tecnologias digitais móveis, em aplicativos e em sites de redes sociais;

- Fotografia, música e audiovisual em suportes digitais móveis;

- Espaços (urbano e ciber) no cenário de mobilidade;

- Publicidade e/ou marketing móvel;

- Mobilidade e educação;

- Jogos digitais móveis;

- Metodologias para o estudo da comunicação digital móvel;

- Jornalismo móvel.

Com base no objetivo deste artigo, selecionou-se as pesquisas referentes ao eixo jornalismo móvel. Assim, o corpus deste trabalho é composto por sessenta (60) investigações, totalizando dezesseis (16) teses e quarenta e quatro (44) dissertações. Todas finalizadas entre os anos de 2005 e de 2020 e produzidas em Programas de Pós-Graduação do Brasil da área de Comunicação e Informação.

\section{$2^{a}$ Etapa}

${ }^{8}$ Disponível em: https://bit. ly/3zm5ACh. Acesso em: 20 ago. 2021.
Descrição e análise:

A fim de alcançar o objetivo proposto, inicialmente, os dados foram organizados em tabelas e quantificados. A ideia era encontrar padrões, variações e ten- 
dências referentes à pesquisa em jornalismo móvel no Brasil. Para isso, realizou-se a leitura de todos os títulos, folhas de rosto, resumos, sumários, e em alguns casos, das introduções das teses e das dissertações.

Com base nos dados coletados, organizados e tabulados, identificou-se as principais características das investigações, as quais serão descritas e analisadas no tópico seguinte com base em seis categorias: ano de finalização, Programas de Pós-Graduação, regiões do Brasil, temáticas, suportes e organizações jornalísticas.

\section{A Pesquisa em Jornalismo Móvel}

Com a organização e tabulação dos dados, chegaram-se aos seguintes resultados acerca das características da pesquisa em jornalismo móvel no Brasil. Quanto ao ano de finalização de teses e dissertações, apesar da primeira dissertação ter sido defendida em 2005, foi somente a partir de 2011 que houve o aumento das investigações, segundo o levantamento (Gráfico 1). A primeira tese foi defendida em 2012.

Observou-se que o início das pesquisas está relacionado ao surgimento de experiências jornalísticas pioneiras para celular no país. Já o crescimento da quantidade de investigações, a partir de 2011, pode ser justificado pelo lançamento de dispositivos móveis como o iPhone e o iPad e de aplicações jornalísticas para esses suportes. O aumento dos cursos de Pós-Graduação no Brasil é outro elemento que pode colaborar para essa elevação. Na área de Comunicação e Informação, houve uma ampliação de 58\% entre os anos de 2006 e $2009^{9}$.

O auge de dissertações finalizadas ocorreu em 2015, com dez (10) pesquisas. Já o pico de teses se deu em 2017, com quatro (04) investigações. Esses trabalhos iniciaram no ano de 2013, uma vez que o tempo de duração dos cursos de mestrado e de doutorado é de dois e quatro anos, respectivamente. Nesse período, entre 2012 e 2013, o crescimento de smartphones e tablets no Brasil ultrapassou $100 \%{ }^{10}$ 10. Com a popularização desses suportes, as investigações começavam a explorar ainda mais este universo. Portanto, é possível que este boom de pesquisas sobre jornalismo móvel esteja relacionado aos desafios dos processos de construção da notícia frente à sociedade conectada.

Após o período de ápice, houve um declínio progressivo na quantidade de trabalhos concluídos. Contudo, no caso das dissertações, a partir de 2018 ocorreu uma estabilidade no número de pesquisas finalizadas. Acredita-se que a diminuição de pesquisas sobre jornalismo móvel esteja relacionada à volatilidade do tema. Isto é, às especificidades dos processos jornalísticos com dispositivos móveis deram lugar aos temas relacionados à desinformação, aos filtros bolha, aos algoritmos, aos conteúdos imersivos (realidade virtual, realidade aumentada e 360 graus). Embora tais discussões integrem o jornalismo móvel, é provável que algumas dissertações e teses que tratam desses assuntos não tenham sido localizadas neste levantamento que buscava por termos relacionados apenas ao jornalismo e à mobilidade.
${ }^{9}$ Disponível em: http://goo. gl/6b8u8L. Acesso: 24 jun. 2017.

${ }^{10}$ Disponível em: https:// bit.ly/3zrDEge. Acesso em 30 jul. 2021. 


\section{Gráfico 1: Número de teses e dissertações por ano de finalização.}

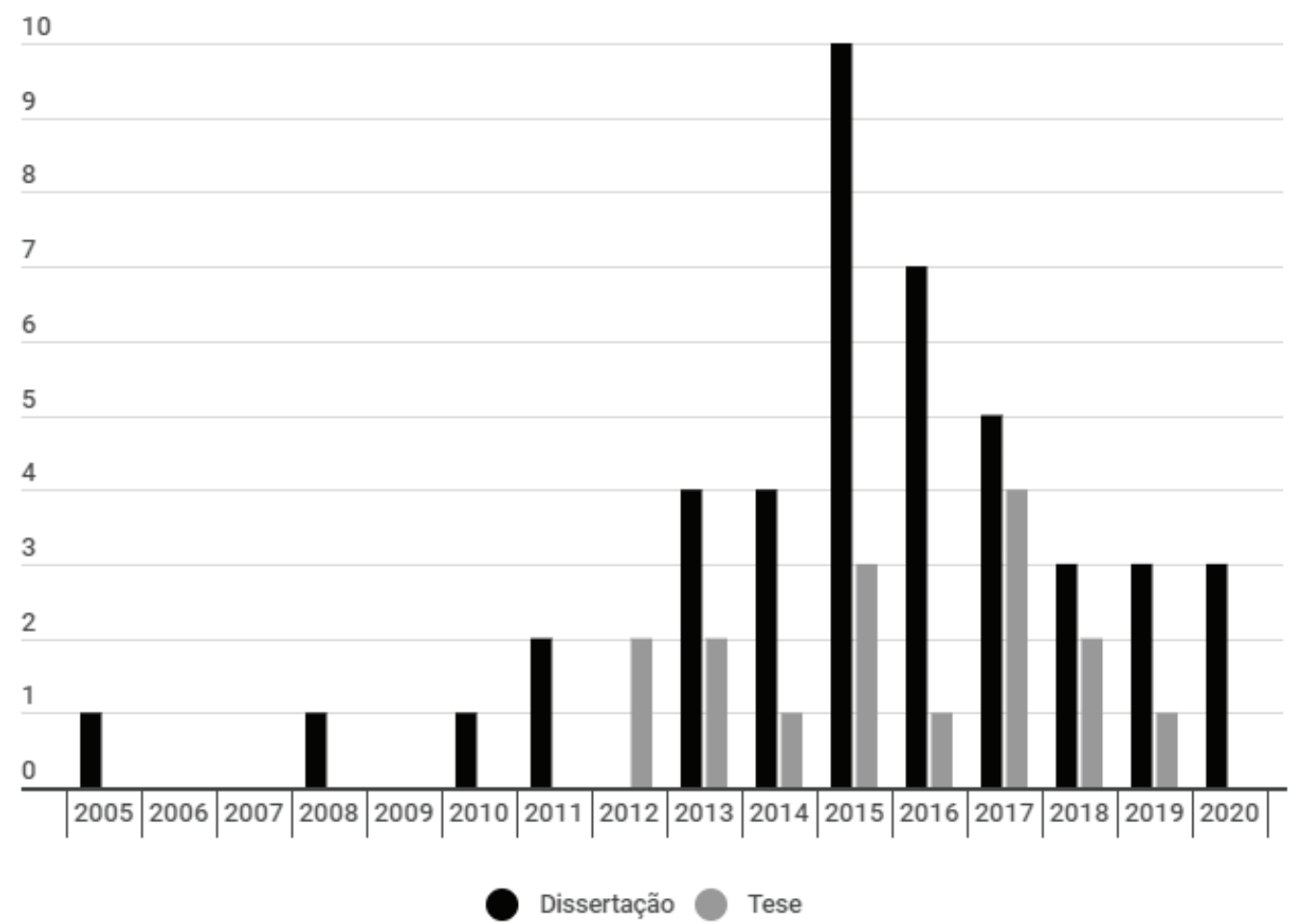

Fonte: Organização da autora.

No que se refere aos Programas de Pós-Graduação onde as teses e as dissertações foram desenvolvidas, destacaram-se como aqueles com maior quantidade de pesquisas sobre jornalismo móvel: o PPG em Comunicação e Cultura Contemporâneas da Universidade Federal da Bahia (PÓSCOM/UFBA) e o PPG em Jornalismo da Universidade Federal da Paraíba (PPJ/UFPB), com oito (08) investigações cada um; o PPG em Comunicação da Universidade Federal do Rio Grande do Sul (PPGCOM/UFRGS) e o PPG em Jornalismo da Universidade Federal de Santa Catarina (PPGJOR/UFSC), com (06) seis pesquisas cada um (Gráfico 2).

Todos os trabalhos do PÓSCOM/UFBA foram realizados entre 2011 e 2015 - até o início do período auge dos estudos sobre jornalismo móvel. Esse dado pode ser justificado pelo fato da instituição ser considerada pioneira nos estudos de jornalismo em ambientes digitais no Brasil. Tal tradição pode ser percebida em trabalhos oriundos do Grupo de Pesquisa em Jornalismo On-line (GJOL), coordenado por Suzana Barbosa e Marcos Palacios, e do Laboratório de Pesquisa em Mídia Digital, Redes e Espaço (LAB404), coordenado por André Lemos.

Nesse sentido, salienta-se ainda que das oito (08) dissertações produzidas no PPJ/UFPB, seis (06) foram orientadas por Fernando Firmino da Silva que é egresso do PÓSCOM/UFBA, integra/ou os grupos citados acima e coordena o Grupo de Pesquisa em Jornalismo e Mobilidade (MOBJOR). Esses trabalhos foram concluídos entre 2017 e 2020 - após o apogeu das investigações. Tal fato demonstra que o PPJ/UFPB tem se tornado referência nos estudos sobre jornalismo móvel nos últimos anos.

O PPGCOM/UFRGS e o PPGJOR/UFSC também são tidos como referências nos estudos de jornalismo em ambiente digital. No PPGCOM/UFRGS, as pesquisas foram realizadas entre 2012 e 2018 - período que vai de antes até depois do auge dos estudos, a maioria no âmbito do Laboratório de Edição, Cultura e Design (LEAD), coordenado por Ana Gruszynski, e do Grupo de Pesquisa em Jornalismo Digital (JORDI), até então coordenado por Luciana Mielniczuk (in memorian).

No PPGJOR/UFSC, as pesquisas ocorreram entre 2013 e 2016 - no início do auge dos trabalhos, a maioria foi realizada sob orientação de Rita Paulino, que integra o Núcleo de Estudos e Produção Hipermídia Aplicados ao Jornalismo (NephiJor). 
Ressalta-se que o PPG em Comunicação Social da Pontifícia Universidade Católica do Rio Grande do Sul (PPGCOM/PUCRS) realiza intensa investigação no âmbito da comunicação móvel, porém apenas uma parte das pesquisas tem como foco o Jornalismo. Dos três (03) estudos mapeados na instituição, todos foram realizados um pouco antes da fase ápice, entre 2013 e 2015, no âmbito do Laboratório de Pesquisa em Mobilidade e Convergência Midiática (UBILAB), coordenado por Eduardo Pellanda.

\section{Gráfico 2: Número de teses e dissertações por Programa de Pós-Graduação.}

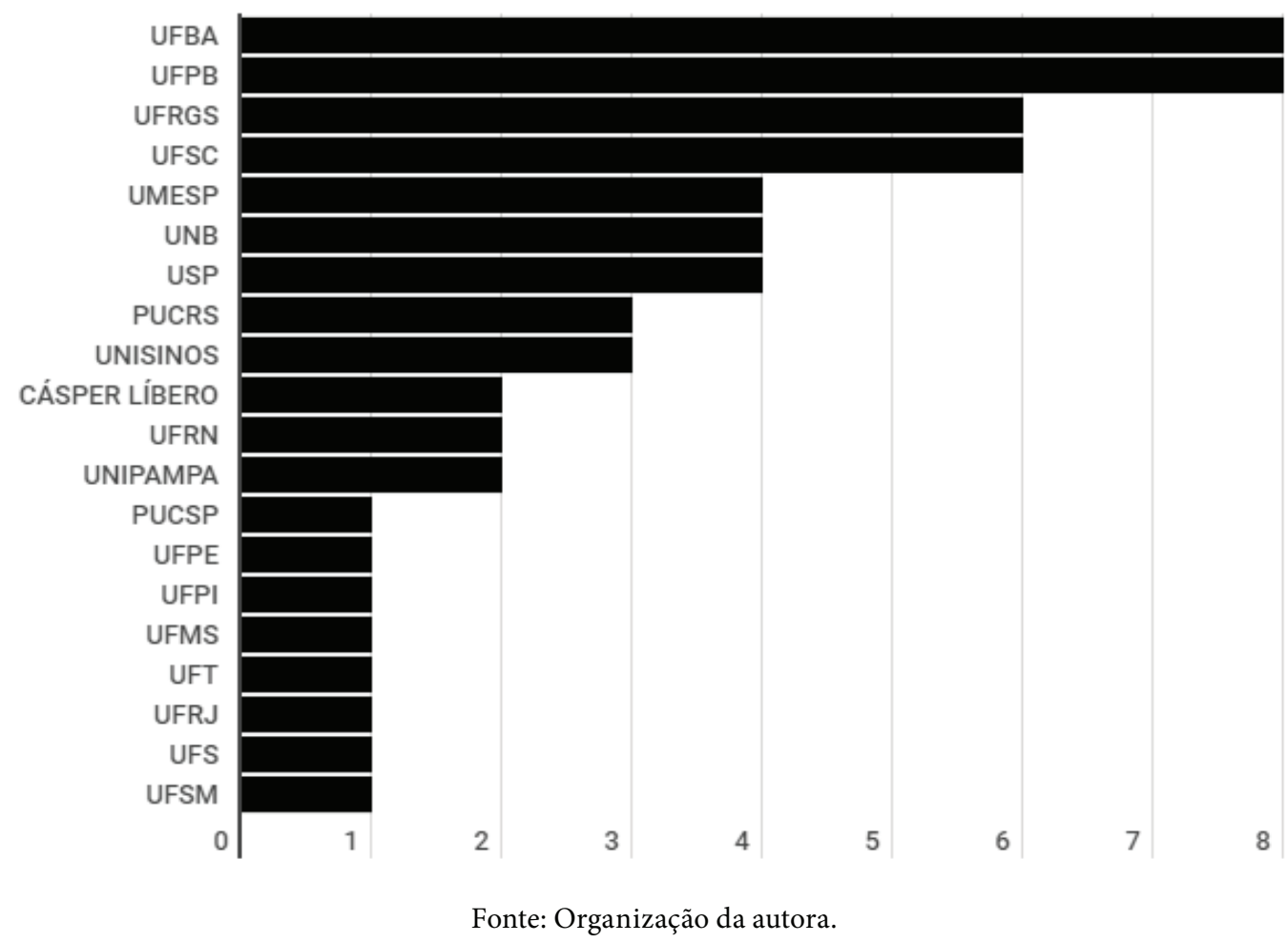

Em relação às regiões do Brasil, $70 \%$ desses PPGs estão concentrados no Nordeste e no Sul. Contabilizou-se vinte e uma (21) pesquisas realizadas na região Nordeste, vinte e uma (21) no Sul, doze (12) no Sudeste, cinco (05) no Centro-Oeste e uma (01) no Norte do país.

Já quanto às temáticas das dissertações e teses, encontrou-se cinco eixos de semelhança conforme as abordagens:

- Produção: abrange dezenove (19) investigações referentes ao processo de produção e/ou de edição de informações jornalísticas realizado por meio de tecnologias móveis, podendo ser referente tanto às práticas no jornalismo móvel quanto no jornalismo impresso, radiofônico, televisivo ou digital;

- Características de produtos: reúne dezoito (18) trabalhos que tratam das especificidades dos produtos jornalísticos em dispositivos móveis. Os trabalhos englobam temas relacionados às características do ciberjornalismo e/ou dos dispositivos móveis em produtos inovadores e/ou oriundos de revistas e jornais impressos, radiojornais, telejornais;

- Produtos multiplataforma: abarca nove (09) pesquisas relacionadas às múltiplas plataformas. Embora esses estudos possam abordar aspectos relacionados ao design, à interface e/ou às características que constituem os produtos jornalísticos para as plataformas móveis, eles analisam também produtos para o impresso (revista e/ou jornal) e/ou para o computador (site).

- Design e interface de produtos: engloba oito (08) estudos que têm como enfoque o design e/ou a interface de produtos jornalísticos para as plataformas móveis. 
- Consumo: engloba seis (06) trabalhos sobre o consumo de produtos jornalísticos em dispositivos móveis.

Tais dados demonstram uma concentração de pesquisas focadas nos produtos $(61,3 \%)$, as quais abarcam as características, o design, a interface e as relações com as múltiplas plataformas. Percebe-se, assim, uma relação entre o surgimento de inovações nos produtos jornalísticos para dispositivos móveis e as temáticas das investigações. Embora em menor fração, as reconfigurações dos processos de produção e de consumo de notícias a partir do uso de tecnologias digitais móveis também integram esta equação.

Quanto aos suportes analisados, observou-se que dezesseis (16) trabalhos tratam de tecnologias digitais móveis (gravadores, câmeras fotográficas, PDA's, netbooks, notebooks, smartphones, tablets e/ou aplicativos de agregadores de conteúdos e/ou de sites de redes sociais), doze (12) versam unicamente a respeito dos tablets, oito (08) tanto sobre tablets quanto sobre smartphones, onze (11) abordam as múltiplas plataformas (impressos, computadores de mesa, smartphones, tablets), dez (10) somente os smartphones, dois (02) apenas os celulares e um (01) exclusivamente os relógios inteligentes (Gráfico 3).

Verificou-se também que as primeiras pesquisas tratam de temas relacionados especificamente aos celulares. A partir de 2011 há um enfoque dos estudos sobretudo para os tablets. A partir de 2015 ocorre um crescimento de investigações que englobam - além dos tablets - os smartphones. Em 2016 e em 2017, os trabalhos com foco apenas nos smartphones apresentavam aumento, sendo que, em 2020, todas as dissertações analisam esse suporte. Entre 2010 e 2019, existem pesquisas que problematizam a forma como as tecnologias digitais móveis podem integrar os processos jornalísticos; e, entre 2011 e 2019, há estudos referentes aos jornais em múltiplas plataformas. Localizou-se um estudo sobre tecnologias vestíveis em 2017.

Mais uma vez, constatou-se que há uma relação entre o lançamento de tecnologias digitais móveis e a apropriação pelo jornalismo com a escolha dos suportes analisados nas pesquisas. Os resultados também podem ser justificados pelas práticas de consumo de notícias. Segundo o Reuters Institute Digital News Report $2021^{11} 11$, no Brasil, desde 2013 há o declínio do consumo por meio de computadores de mesa e o crescimento através de smartphones. Embora o uso de tablets tenha tido uma expansão no início da década, desde 2014 tem apresentado certa diminuição. Em 2017, o uso de smartphones superou o de computadores. Desde então, há uma tendência de aumento do consumo de notícias por meio de smartphones em detrimento de computadores de mesa e tablets.

\section{Gráfico 3: Número de teses e dissertações por suporte analisado.}

${ }^{11}$ Disponível em: https:// bit.ly/3DgKacf. Acesso em: 10 jul. 2021.

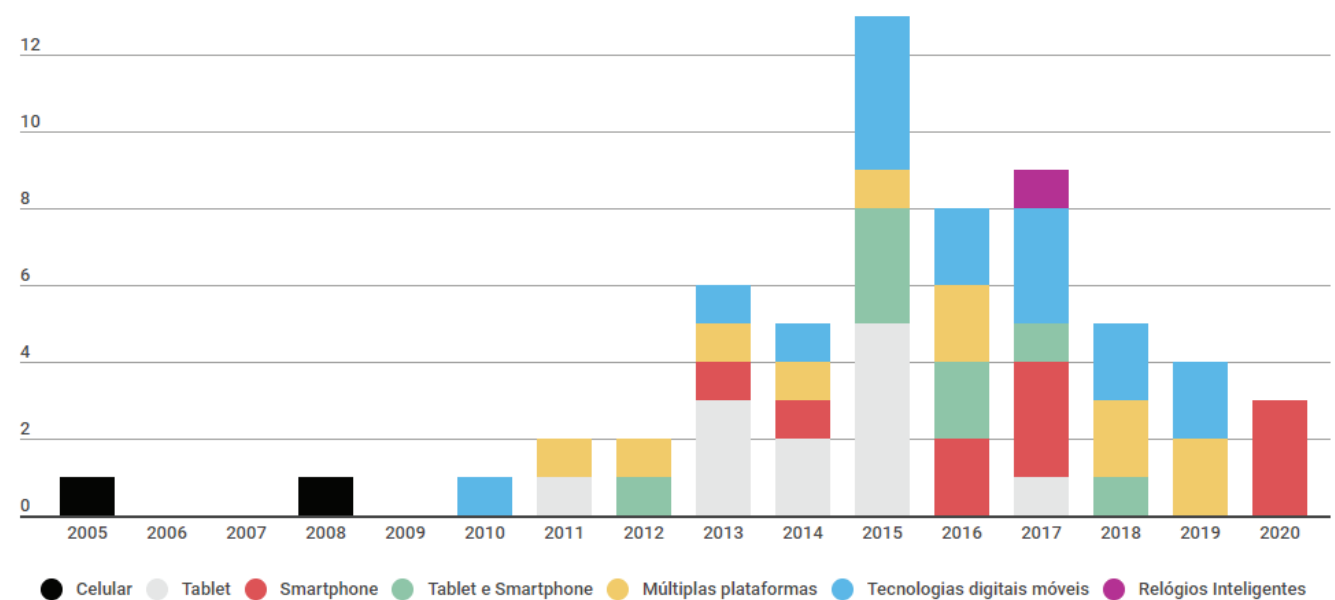

Fonte: Organização da autora. 
Por fim, no que diz respeito às organizações jornalísticas analisadas, sobressaem-se os trabalhos que têm como objetos empíricos os veículos noticiosos de tradição impressa (jornais e revistas) nacionais (Figura 1). Dentre as empresas que têm seus processos e produtos mais investigados estão: Grupo Globo (15), O Estado de S. Paulo (11), Zero Hora (08), The New York Times (07), Folha de S. Paulo (06), Veja (04), Época (03), Katachi (03) e Wired (03).

\section{Figura 1: Nuvem de palavras com os nomes dos veículos jornalísticos investigados.}

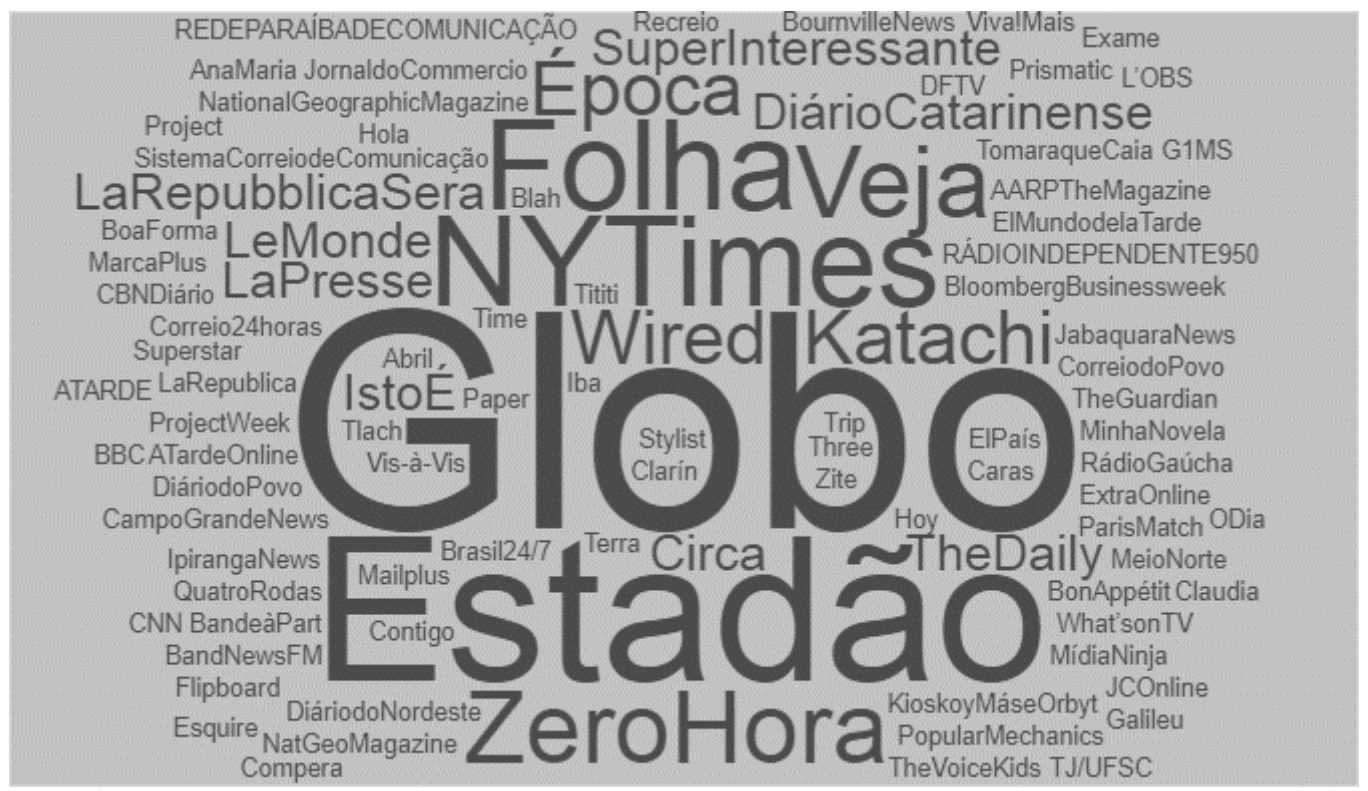

Fonte: Organização da autora.

Portanto, identificou-se que, no Brasil, a pesquisa em jornalismo móvel tem as seguintes características: inicia-se nos primeiros anos do século XXI, tendo como auge o período de 2015 a 2017; concentra-se em PPGs das regiões Nordeste e Sul do país, com destaque para o PÓSCOM/UFBA, o PPJ/UFPB, o PPGCOM/ UFRGS e o PPGJOR/UFSC; foca-se em temáticas referentes aos produtos noticiosos e em objetos empíricos relacionados aos suportes recém lançados no mercado e apropriados pelas organizações jornalísticas tradicionais.

\section{Considerações Finais}

Este artigo buscou identificar as características de teses e dissertações sobre jornalismo móvel produzidas em Programas de Pós-Graduação do Brasil. Em um cenário no qual a mobilidade é a característica fundamental da sociedade (HANNAM; SHELLER; URRY, 2006), a mobilidade também passa a ser um atributo primordial do jornalismo (DUFFY et al., 2021). Nesse sentido, dentre os resultados desta pesquisa, destaca-se a relação da expansão dos estudos sobre jornalismo móvel com o lançamento de tecnologias digitais móveis no mercado e a apropriação pelos veículos jornalísticos para a produção e a circulação de conteúdos e pelo público para o consumo. Nesse sentido, verificou-se que:

- no início do século XXI, os primeiros estudos tratavam das experiências jornalísticas pioneiras para os celulares;

- a partir de 2011, logo após o lançamento e a popularização de iPhones/smartphones e de iPads/tablets, houve um crescimento das pesquisas acerca do jornalismo móvel; com a expansão dos iPads/tablets, as investigações focavam principalmente nas linguagens e nos formatos para esses suportes; 
- a partir de 2016, conforme o consumo de notícias através de iPhones/smartphones aumentava, a atenção dos trabalhos recaia para esses suportes;

- a partir de 2018, houve uma queda nos estudos que abordavam as especificidades do jornalismo móvel.

Tais resultados mostram a fluidez e as constantes mudanças (DUFFY et al., 2021) deste campo de investigação que em apenas quinze anos apresentou diferentes focos de pesquisa. Eles exibem também a relação entre os desafios enfrentados pela prática jornalística com o que é pesquisado na academia. Em um momento no qual a sociedade começava a se conectar, surgindo novas práticas de produção e de consumo de informações jornalísticas, assim como novos produtos noticiosos, os estudos voltam-se para tais questões. Conforme o jornalismo móvel torna-se ubíquo (SALAVERRÍA, 2016), a desinformação, os filtros bolha, os algoritmos, os conteúdos imersivos começam a fazer parte do cotidiano da sociedade e, por conseguinte, dos veículos jornalísticos. Assim, os trabalhos passam a pautar tais desafios. Nesse último momento, embora as pesquisas tratem de questões relacionadas à sociedade móvel (AGUADO; MARTÍNEZ, 2008a), os conceitos principais mudam e, por isso, há esse decrescimento na quantidade de dissertações e teses localizadas neste artigo.

Com a pandemia de Covid-19, percebe-se que surgiram novos desafios para o jornalismo com dispositivos móveis e, consequentemente, para os estudos em jornalismo móvel. A necessidade de isolamento físico fez com que as pessoas passassem mais tempo conectadas, aumentando o consumo de notícias por dispositivos móveis; mas também colocou em evidência práticas como: a redação virtual, o uso de imagens (estáticas e em movimento) feitas pelo público através de dispositivos móveis, as entrevistas realizadas por meio desses suportes (por voz ou aplicativos de mensagem/videoconferência).

Portanto, a aceleração tecnológica e, por conseguinte, a rapidez com que ocorrem essas transformações no jornalismo com dispositivos móveis configuram-se como desafios para este campo de investigação. Desse modo, espera-se que este mapeamento sobre os primeiros quinze anos de pesquisa em jornalismo móvel no Brasil contribua para uma melhor compreensão do desenvolvimento desta subárea dos estudos de jornalismo.

\section{Referências}

ABREU, G. F. de. Reconfigurações da produção jornalística a partir do uso do smartphone. 2021. Dissertação (Mestrado em Comunicação, Linguagens e Cultura). Programa de Pós-Graduação em Comunicação, Linguagens e Cultura, Universidade da Amazônia, Belém, 2021.

AGUADO, J. M.; CASTELlET, A. Contenidos digitales en el entorno móvil: mapa de situación para marcas informativas y usuários. In: BARBOSA, S.; MIELNICZUK, L. (org.). Jornalismo e Tecnologias Móveis. Covilhã: Livros LabCOM, 2013.

AGUADO, J. M.; MARTÍNEZ, I. J. El dispositivo móvil como encrucijada cultural. In: AGUADO, J. M.; MARTÍNEZ, I. (org.). Sociedad móvil. Tecnología, identidad y cultura. Madrid: Biblioteca Nueva, 2008a.

AGUADO, J. M.; MARTÍNEZ, I. J. La cuarta pantalla: industrias culturales y contenido móvil. In: AGUADO, J. M.; MARTÍNEZ, I. (org.). Sociedad móvil. Tecnología, identidad y cultura. Madrid: Biblioteca Nueva, 2008b. 
ALEXANDRE, T. B. Linguagem jornalística autóctone para dispositivos móveis. 2021. Tese (Doutorado em Ciências da Comunicação). Programa de Pós-Graduação em Ciências da Comunicação, Universidade do Vale do Rio dos Sinos, São Leopoldo, 2021.

BARBOSA, S.; SEIXAS, L. Jornalismo e dispositivos móveis: percepções, usos e tendências. In: BARBOSA, S.; MIELNICZUK, L. (org.). Jornalismo e Tecnologias Móveis. Covilhã: Livros LabCOM, 2013.

BELOCHIO, V. de C. Jornalismo em contexto de convergência: implicações da distribuição multiplataforma na ampliação dos contratos de comunicação dos dispositivos de Zero Hora. 2012. Tese (Doutorado em Comunicação e Informação). Programa de Pós-Graduação em Comunicação e Informação, Universidade Federal do Rio Grande do Sul, Porto Alegre, 2012.

CANAVILHAS, J.; SATUF, I. Jornalismo em transição: do papel para o tablet... ao final da tarde. In: FIDALGO, A.; CANAVILHAS, J. (org.). Comunicação digital. 10 Anos de investigação. Coimbra: Minerva Coimbra, 2013.

CANAVILHAS, J. Modelos informativos para aparatos móviles: información hipermultimediática y Personalizada. In: MOLINA, S. G. et al. (org.). Hacia el Periodismo Móvil. Santiago de Chile: RMC/CI, 2013.

CANAVILHAS, J. Epistemology of mobile journalism. A review. Profesional de la información, v. 30, n. 1, 2021.

CARMO, F. C. do. Jornalismo móvel: um estudo do noticiário produzido para celulares. 2008. Dissertação (Mestrado em Comunicação). Faculdade de Comunicação Social, Cásper Líbero, São Paulo, 2008.

CUNHA, R. do E. S. da. Design de informação em produtos jornalísticos para tablets: uma comparação Brasil-Espanha. 2015. Tese (Doutorado em Comunicação e Culturas Contemporâneas). Programa de Pós-graduação em Comunicação e Cultura Contemporâneas, Universidade Federal da Bahia, Salvador, 2015.

DUFFY, A. et al. (org.). Mobile News. Journalism's shift from fixed to fluid. New York/ London: Routledge, 2021.

EMPINOTTI, M. L. Taxonomia para classificação de aplicativos noticiosos para smartphones. Um sistema baseado em funcionalidades e affordances. 2020. Tese (Doutorado em Estudos de Comunicação: Tecnologia, Cultura e Sociedade). Universidade da Beira Interior, Covilhã, 2020.

FERREIRA, P. H. de O. Notícias no celular: uma introdução ao tema. 2005. Dissertação (Mestrado em Ciências da Comunicação). Programa de Pós-Graduação em Ciências da Comunicação, Universidade de São Paulo, São Paulo, 2005.

FIDALGO, A. PUSHED NEWS: When the news comes to the cellphone. Brazilian Journalism Research, v. 5, n. 2, 2009.

FIDALGO, A.; CANAVILHAS, J. Todos os jornais no bolso: pensando o jornalismo na era do celular. In: RODRIGUES, C. (org.). Jornalismo On-line: modos de fazer. Rio de Janeiro: PUC-Rio: Sulina, 2009. 
FONSECA, A. dos A. A imersão como categoria estruturante e indutora de inovações no jornalismo em redes digitais. 2020. Tese (Doutorado em Comunicação e Cultura Contemporâneas). Programa de Pós-Graduação em Comunicação e Cultura Contemporâneas, Universidade Federal da Bahia, Salvador, 2020.

GOGGIN, G.; LING, R.; HJORTH, L. "Must-Read” Mobile Technology Research: A Field Guide. In: GOGGIN, G.; LING, R.; HJORTH, L. (org.). Mobile Technologies. New York: Routledge, 2015.

HANNAM, K.; SHELLER, M.; URRY, J. Editorial: Mobilities, Immobilities and Moorings. Mobilities, v. 1, n. 1, 2006.

HILL, S.; BRADSHAW, P. Mobile-First Journalism. Producing News for Social and Interactive Media. London/ New York: Routledge, 2019.

LEMOS, A. Cultura da Mobilidade. Revista Famecos, n. 40, 2009.

LOPES, M. I. V. de. Pesquisa em comunicação. São Paulo: Edições Loyola, 2010.

MARQUES, A. O campo jornalístico e a pauta: um olhar sobre a produção de conteúdos para tablets. 2017. Tese (Doutorado em Comunicação). Programa de Pós-Graduação em Comunicação Social, Universidade de Brasília, Brasília, 2017.

MIELNICZUK, L. O celular afronta o jornalismo. In: BARBOSA, S.; MIELNICZUK, L. (org.). Jornalismo e Tecnologias Móveis. Covilhã: Livros LabCOM, 2013.

OLIVEIRA, V. R. de. Jornalismo em dispositivos móveis: uma concepção estratégica de conteúdos noticiosos para tablets e smartphones. 2017. Tese (Doutorado em Comunicação). Programa de Pós-Graduação em Comunicação Social, Universidade de Brasília, Brasília, 2017.

PALACIOS, M. O mundo no bolso e o contexto na palma da mão. In: BARBOSA, S.; MIELNICZUK, L. (org.). Jornalismo e Tecnologias Móveis. Covilhã: Livros LabCOM, 2013.

PALACIOS, M. et al. Jornalismo móvel e inovações induzidas por affordances em narrativas para aplicativos em tablets e smartphones. In: CANAVILHAS, J.; SATUF, I. (org.). Jornalismo para Dispositivos Móveis: produção, distribuição e consumo. Covilhã: Livros LabCom, 2015.

PAULINO, R. Interatividade e visualização de notícias em apps: um design baseado em Cards. In: Encontro Nacional de Pesquisadores em Jornalismo - SBPJOR, 15, 2017, São Paulo. Anais... São Paulo: SBPJOR/USP, 2017.

PAVLIK, J. Journalism and New Media. New York: Columbia University Press, 2001.

PAVLIK, J. Ubiquidade: o 7.0 princípio do jornalismo na era digital. In: CANAVILHAS, J. (org.). WebJornalismo: 7 Caraterísticas que marcam a diferença. Covilhã: Livros LabCOM, 2014.

PELLANDA, E. Internet móvel: Novas relações na cibercultura derivadas da mobilidade na comunicação. 2005. Tese (Doutorado em Comunicação Social). Programa de Pós-Graduação em Comunicação Social, Pontifícia Universidade Católica do Rio Grande do Sul, Porto Alegre, 2005. 
PELLANDA, E. C. Comunicação móvel: das potencialidades aos usos e aplicações. Em Questão, v. 15, n. 1, 2009.

PELLANDA, E. C., et. al. Mobilidade e jornalismo digital contemporâneo: Fases do jornalismo móvel ubíquo e suas características. In: CANAVILHAS, J.; RODRIGUES, C. (org.). Jornalismo móvel: linguagem, géneros e modelos de negócio. Covilhã: Livros LabCOM, 2017.

QUINN, S. Knowledge Management in the Digital Newsroom. Oxford: Focal Press, 2002.

QUINN, S. MoJo - Mobile Journalism in the Asian Region. Singapore: Konrad-Adenauer-Stiftung, 2009.

REZENDE, I. S. Aplicativos agregadores de informação jornalística para dispositivos móveis: Uma exploração pela Teoria Ator-Rede. 2016. Tese (Doutorado em Ciências da Comunicação). Universidade da Beira Interior, Covilhã, 2016.

SALAVERRÍA, R. Los medios de comunicación que vienen. In: SÁDABA CHALEZQUER, C.; GARCÍA ANILÉS, J. A.; MARTÍNEZ-COSTA, M. del P. (org.). Innovaciónn y desarrollo de los cibermedios en España. Navarra: Ediciones Universidad de Navarra, 2016.

SALAVERRÍA, R.; LIMA-SANTOS, M. F. de. Towards Ubiquitous Journalism: Impacts of IoT on News. In: VAZQUEZ-HERRERO, J. et al. (org.) Journalistic Metamorphosis. Media Transformation in the Digital Age. Cham: Springer, 2020.

SHELLER, M. News now. Interface, ambience, flow, and the disruptive spatio-temporalities of mobile news media. Journalism Studies. v. 16, n. 1, 2015.

SILVA, F. F. da. Jornalismo móvel digital: o uso das tecnologias móveis digitais e a reconfiguração das rotinas de produção da reportagem de campo. 2013. Tese (Doutorado em Comunicação e Culturas Contemporâneas). Programa de Pós-Graduação em Comunicação e Cultura Contemporâneas, Universidade Federal da Bahia, Salvador, 2013.

SILVEIRA, S. C. da. Conteúdo jornalístico para smartphone: o formato da narrativa sistêmica no jornalismo ubíquo. 2017. Tese (Doutorado em Ciências da Comunicação). Programa de Pós-Graduação em Ciências da Comunicação, Universidade de São Paulo, São Paulo, 2017.

SOUSA, M. E. de. Jornalismo em wearables: apontamentos iniciais sobre a circulação de notícias em smartwatches. In: SILVA, F. F. da (org.). Transmutações no jornalismo. Campina Grande: EDUEPB, 2016.

SOUSA, M. de C. E. de. Jornal e Mobilidade: Reconfigurações do Impresso ao Multiplataforma. 2018. Tese (Doutorado em Comunicação e Informação). Programa de Pós-Graduação em Comunicação e Informação, Universidade Federal do Rio Grande do Sul, Porto Alegre, 2018.

SOUZA, D. R. Jornalismo em novas telas: a distribuição de notícias nos wearables. 2014. Monografia (Graduação em Jornalismo) - Pontifícia Universidade Católica do Rio Grande do Sul. Porto Alegre. 2014. 
WESTLUND, O. MOBILE NEWS. A review and model of journalism in an age of mobile media. Digital Journalism, v. 1, n. 1, 2013.

WESTLUND, O. The production and consumption of mobile news. In: GOGGIN, G; HJORTH, L. (org.) The mobile media companion. New York: Routledge, 2014. 